\title{
Forward to the special issue-International Conference on Environment: Survival and Sustainability (ESS 2007)
}

\author{
Hüseyin Gökçekuş · Umut Türker · \\ Münir Öztürk
}

Published online: 7 November 2008

(C) Springer-Verlag 2008

Environment is a subject that must be brought to the top of international agendas if the threats to sustainability and survival are to be countered. Economic development cannot eliminate poverty without conserving natural resources and maintaining ecosystem services, nor can productive activity ignore the significant effects of resource extraction and waste generation. Therefore, environment must be the central focus of both international and national programs at all levels.

The International Conference on the Environment: Survival and Sustainability (ESS2007), organized by the Near East University between 19 and 24 February 2007 was held in Lefkosa, Turkish Republic of Northern Cyprus. The conference aimed to contribute to the worldwide debate and tried to create a multi-disciplinary discussion forum where experts from various disciplines were able to discuss environmental issues in 21 different fields. The Conference brought together 2,052 participants from 108 countries and 1,463 papers including plenary talks, orally presented papers and posters. Posters were of exceptional quality and left participants were very impressed. The papers dealt with various kinds of environmental threats and proposed solutions at all scales.

H. Gökçekuş $(\bowtie) \cdot$ U. Türker

Near East University, Nicosia, North Cyprus

e-mail: ess2007@neu.edu.tr

U. Türker

e-mail: uturker@neu.edu.tr

M. Öztürk

Ege University, Izmir, Turkey

e-mail: munirozturk@gmail.com
This special issue of the Environmental Geology contains selected papers by researches representing different countries and disciplines. The readers will notice the wide range of topics displayed by the articles included. They cover a variety of topics displaying different environmental problems and their solutions on the base of survival and sustainability of the environment. The energy issues, the water quality concerns, the solid waste management, earthquake assessment and mine wastes are some of the topics dealt with in this special issue. All the papers contain ideas and results relating to the various problems in the preservation and management of environment, which are an important part of the world ecosystem.

As a guest editor, I would like to express my gratitude to the Editorial Board of the Environmental Geology for including some selected papers of the ESS2007 conference in this issue. I hope that the articles will provide the readers with a general idea regarding the content of the conference.

Prof. Dr. Hüseyin Gökçekuş President of the Conference and Organizing Committee Vice Rector of the Near East University Lefkosa-TRNC 